\title{
Remote Sensing Studies for Mapping of Iron Oxide Regions, South of Kerman, IRAN
}

\author{
Aref Shirazi \\ Amirkabir University of \\ Technology (Tehran \\ Polytechnic) \\ Mining and Metallurgical \\ Engineering Department \\ Tehran, IRAN
}

\author{
Ardeshir Hezarkhani \\ Amirkabir University of \\ Technology (Tehran \\ Polytechnic) \\ Mining and Metallurgical \\ Engineering Department \\ Tehran, IRAN
}

\author{
Adel Shirazy \\ Shahrood University of \\ Technology \\ Faculty of Mining, Petroleum \\ and Geophysics \\ Shahrood, IRAN
}

\begin{abstract}
Due to the economic and industrial importance of iron in the development of human societies, in recent decades, extensive explorations have been carried out on minerals containing this valuable metal. Remote sensing techniques are known as one of the most powerful tools for regional exploration of this mineral. In this study, various methods of remote sensing such as band ratios (BR), false color combinations (FCC), least square fitting (LS-Fit), spectral angle mapper (SAM), and finally principal components analysis (PCA) for mapping iron minerals in the Hana district, south of Kerman province, were used. The results of these methods were compared with each other as well as with the results of studies and field surveys. After reviewing and comparing the results, it was determined that in the studied region, spectral angle mapper (SAM) method has higher accuracy for mapping of oxidation regions and iron minerals.
\end{abstract}

Keywords: Remote Sensing; Image processing methods; Iron Altration; SAM, LS-Fit, FCC, PCA, BR

\section{INTRODUCTION}

Iron as a strategic element plays an important role in the development of industry and economics of countries [1]. The need to extract this element from the minerals in nature reveals the importance of the regional exploration of these minerals. On the other hand, the use of various remote sensing techniques will increase the speed of operation and significantly reduce the cost of finance [3, 4]. In this study, using remote sensing methods including band ratios (BR), false color combinations (FCC), least square fitting (LS-Fit), spectral angle mapper (SAM), and principal components analysis (PCA) and also considering the geological features of the study area, the detection of oxidation regions and iron minerals in the area of Hana, located in the south of Kerman province, is discussed.

\section{DATA AND RESEARCH METHODS}

\subsection{Regional Geological Setting}

The study area is located in the south of Kerman province and Kahnouj city, in the geological map of 1: 100,000 Hana (Figure 1) [2]. The area consists of four geological sequences which are described below :

- Volcanic - Pyroclastic - Sedimentary sequence :

This sequence consists of the oldest rocks of the region with the Eocene age, which is characterized in the Fark River region with the units of green tuff and sandstone and limestone, including pyroclastic sediments, microdiorite dikes, tuff, andesite, conglomerate, sandstone and carbonate rocks.

- $\quad$ Sedimentary - Sedimentary - Volcanic sequence : Includes conglomerates, sandstone, marl , dacitic massive tuffs and fossil limestone and bioclasts.

- Volcanic series :
This series introduces volcanics belonging to the after Oligomiocene and contains acidic up to the intermediate volcanic rocks, granite and granodiorite dikes, Porphyry and diabase rocks that dikes have penetrated into oligomiocene rocks.

- Sedimentary series :

The Neogene layers in the lower parts include red gypsum sandstones representing semi-arid conditions of sedimentary environments, and the upper layers are conglomerates.

Quaternary sediments in the form of sandy dunes and alluvial plains cover most of the southern and western parts of the area and are located on Neogene sediments [2].

The northern part forms the Jabal Barez river basin. This area includes Eocene-Quaternary sediments along with pyroclastic and granite sediments. The southern part of the area consists of a deep river basin, which is mainly covered with a thick layer of gravel, which forms a whole bulky desert.

The oldest observable rocks belong to the Eocene. In the "Fark" river, there are green tuff, sandstone and carbonate layers, and in the "Freezu" mountain range, agglomerate, rhyolite, rhyolitic tuff, conglomerate and dacitic tuff, the middle Eocene have been created.

In the north-eastern part of the region, there are acidic up to the intermediate volcanics, the broadest of which are green hornblend granites. The lower parts of it are often covered with tuff and conglomerate, which is the same process. In parts of the region there are rhyodactic masses and under them there are intrusive masses of quartz diorite to diorite, which are in some places outcrop.

In the northeastern and eastern part of the region, we also have a density of faults and fractures that there are lack of the trend and are often intersecting fractures [2]. 


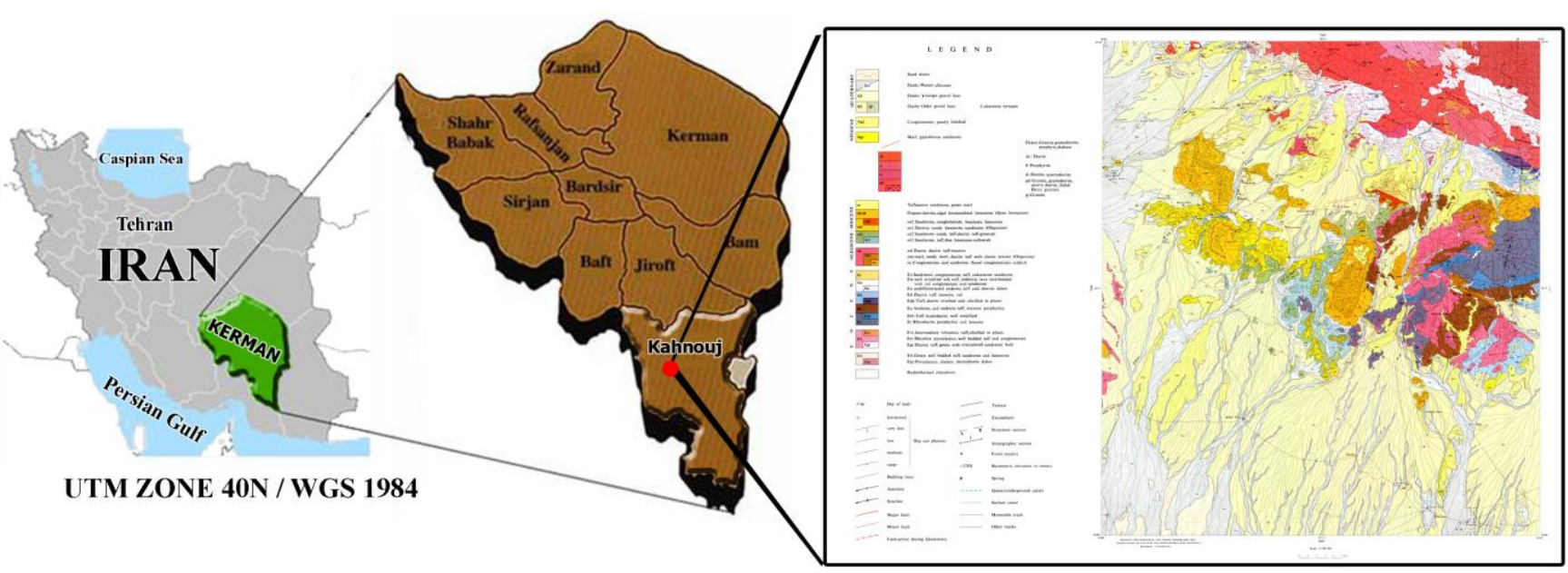

Figure 1. Location of the study area and its geological map [2].

\subsection{Satellite Remote Sensing Data}

In this study, the image of the ASTER Satellite Sensor was used. ASTER (Advanced Spaceborne Thermal Emission and Reflection Radiometer) is a high resolution imaging instrument that is flying on the Terra satellite [5]. ASTER will obtain detailed maps of land surface temperature, emissivity, reflectance and elevation of the Earth.

ASTER has three sensors to measure and record the reflected and emitted Electromagnetic Radiation (EMR). They are working in different wavelength regions the Visible and Near Infrared (VNIR) between 0.52 and $0.86 \mu \mathrm{m}$, Short Wave Infrared (SWIR) between 1.6 and $2.43 \mu \mathrm{m}$, and Thermal Infrared (TIR) between 8.125 and $11.65 \mu \mathrm{m}$. ASTER data consists of 14 spectral bands 3 VNIR, 6 SWIR, and 5 TIR with 15,30 , and $90 \mathrm{~m}$ spatial resolution, espectively [6]. The VNIR, SWIR and TIR wavelength regions provide complementary data for lithological mapping [7].

Geometric corrections were made using the satellite ETM $^{+}$ satellite image on the study area image. In order to ensure the results, IAR Reflectance radiometric corrections were applied to the region image and the results for applying different types of processes were introduced into ENVI software[8].

\subsection{Band Ratios (BR) Method}

In general, all materials are composed of atoms and molecules with a specific composition [9]. Therefore, various materials, depending on the structure, absorb or emit electromagnetic radiation at special wavelengths [10]. So that the wavelength curve and radiant energy for each object are unique and this is a clear feature of remote sensing science [11]. The result of dividing the values of the brightness of the pixels in a spectral band into another band is called the band ratio. And as a result, new lighting levels or, in other words, a new image are created. Band ratios method is used to detect complications that are not visible in the image of single bands [12].

This method is applicable to the recognition of the spectral reflection of various phenomena for the appearance of a particular phenomenon. Relative images that are based on the reflection characteristics of altered minerals and by dividing the digital values of a spectral band into another band are important in identifying altered areas [13].

In order to determine the alteration areas with respect to the spectral characteristics of the index minerals in any kind of alteration, the bands proportions can be defined. Many band ratios have been identified for the identification of various types of minerals in the case of ASTER data [14].

The results of applying band ratios method are gray-scale images that alone are not a valid criterion for determining the target areas in the study area. It only identifies the areas most likely to have the desired minerals or, in general, the objects to be searched for. Using false color combinations (RGB images) can be produced that make the interpretation and conclusions based on them more reliable and more practical [15].

\subsection{False Color Combinations ${ }^{1}$ Method}

The importance of displaying the color combination of images in remote sensing can be considered due to their effectiveness in visual interpretation of various effects. One of the effective methods for identifying and separating various geological units is the false color combination (FCC) method [16].

The false color combination is a combination of three different bands combined in red, green, and blue (RGB) colors. If the combined bands of red, green, and blue wavelengths are the visible spectrum of electromagnetic spectrum, the resulting image will be a true color combination. If a different combination of red, green and blue bands or other bands of the electromagnetic spectrum is used, a false color image will be obtained that is not similar to the surface of the earth and its colors [17].

\footnotetext{
${ }^{1}$ FCC
} 
In making false color combinations it is better to use bands that have less correlation. Since the interaction of different wavelengths of electromagnetic energy is different in dealing with rock units, the sensitivity of the human eye to minor changes in color is much greater than its sensitivity to changes in black and white images. Choosing the best band combination depends on the target [18].

Three images can be combined to make the images visible for viewing in three blue, green, and red wavelengths (original RGB color combinations). In this study, this combination has been used to display several images in a single image and simultaneously display different information from a single point [19].

Calculation of the optimum index factor amount (OIF) is required to obtain the best false color combination (OIF of the higher color combinative with more information). The formula below shows the OIF calculation method [20].

$$
O I F=\frac{\sum_{k=1}^{3} S_{k}}{\sum_{j=1}^{3} r_{j}}
$$

In formula $1: \mathrm{S}_{\mathrm{k}}$ is the standard deviation of the $\mathrm{k}$ band, $\mathrm{r}_{\mathrm{j}}$ is the two-band correlation coefficient of the three-band combination [21]. Sometimes visually, the false color combinations containing major information are determined by the variety of colors [22].

\subsection{Principal Components Analysis (PCA)}

One of the methods used to reduce the correlation between multivariate data and increase the distinction is the main component analysis (PCA) method. The purpose of this method is to compress data and eliminate redundant data in order to save time and money. By using the PCA method, we can replace many independent and correlated variables with a limited number of new variables, which are called principal components and are not interconnected [23]. In this way, the dimensions of the problem are reduced. In general, the purpose of this method is to compress all the information contained in a main dataset composed of $\mathrm{n}$ channels into less than $\mathrm{n}$ channels or new components. Finally, the components are used instead of the original data [24].

In general, this approach reduces the compatibility between different bands data, and new information is obtained and sent to PC channels. By creating a combination of PC channels and dual-source bands, images can be created to illustrate the effects. This technique is a eigenvectors based method, using eigenvalues and eigenvectors, identifies directions with maximum variability and then decreases the dimensions of variables by defining new variables that are linear combinations of the initial variables [25]. New variables that are the product of the linear combination of initial variables do not show correlation between themselves [26].
To compute the main components, at first the variance, covariance, or matrix of correlation between the bands are formed and then eigenvalues and eigenvectors of this matrix are calculated. Because covariance is dependent on the unit of measurement of data and the bands of different bands do not have the same reflexion unit, it is better to use the correlation matrix [27].

For each principal component, an image is calculated from its eigenvectors. The numerical values of the principal component image are calculated using the values of numerical values in the initial images and the components of the eigenvectors as follows:

$$
\alpha=\operatorname{Cos}^{-1}\left[\frac{\sum_{i=1}^{n b} x_{i} r_{i}}{\left(\sum_{i=1}^{n b} x_{i}^{2}\right)^{\frac{1}{2}}\left(\sum_{i=1}^{n b} r_{i}^{2}\right)^{\frac{1}{2}}}\right]
$$

In formula $2: \mathrm{P}_{\mathrm{k}}$ is the numerical value of the desired pixel for the $\mathrm{k}$ th principal component, DN (i) The numeric value of the $\mathrm{i}$-th band for the desired pixel, $\mathrm{a}_{\mathrm{ik}}$ is the amount of the load obtained from the eigenvectors of the $\mathrm{k}$ component in the $\mathrm{i}$-th band. Thus, for each principal component or eigenvectors, an image is obtained that represents the variability in its direction [28].

\subsection{Least Square Fitting (LS-Fit) Method}

In the regression least squares method, a band is estimated based on the linear combination of other bands using the least squares of errors [29]. In this method, the band of the mineral in question is high in adsorption with the rest of the bands, will be divided and the best areas will be detected with pixels containing those minerals $[30,31]$.

\subsection{Spectral Angle Mapper (SAM) Method}

Spectral angle mapping (SAM) method is an image classification method by calculating the similarity between the image spectrum and a reference spectrum (e.g., spectral libraries) [29]. The algorithm of this method calculates the similarity between two spectra by the spectral angle between them [32]. In fact, by transforming the spectra into a vector in a space in the number of dimensions of the bands, the angle between the two vectors is calculated (See figure 2) [33] .

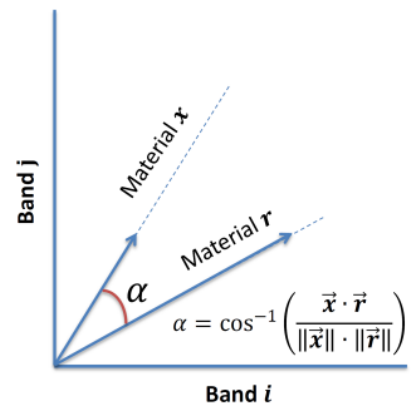

Figure. 1 Example of SAM classification in case of 2 spectral bands. Scalar product between unknown material $\mathrm{x}$ and library sample $\mathrm{r}$ [33]. 
In this method, the direction is important for calculating vectors, not length. Therefore, other factors are not considered in this method. In fact, the more the angle (between 0 and 1) is less, the more accurate it will be. If the value is 0 , the whole image is identified as the desired phenomenon. To compare a pixel, the desired pixel spectrum is plotted from the examined area with the same pixel spectrum in the laboratory (library) on two bands in a coordinate axis. Then the points are connected to the coordinate center, and the angle between the two lines is used as the pixel identification angle. If the $n$ bands are used to identify the phenomenon concerned, the following formula is used to obtain an angle [34].

$$
\alpha=\operatorname{Cos}^{-1}\left[\frac{\sum_{i=1}^{n b} x_{i} r_{i}}{\left(\sum_{i=1}^{n b} x_{i}^{2}\right)^{\frac{1}{2}}\left(\sum_{i=1}^{n b} r_{i}^{2}\right)^{\frac{1}{2}}}\right]
$$

In formula $3: \mathrm{nb}$ is the number of bands. unknown material $\mathrm{x}$ and library sample $\mathrm{r}$.

\section{RESULTS AND DISCUSSION}

In this section, the results of each of the methods described in the previous section are presented.

\subsection{Band Ratios (BR) Method}

In the study area, a ratio of $2 / 1$ to show Iron(II) oxides [35], $3 / 2$ ratio to reveal vegetation coverings and a ratio of $5 / 7$ to show hydroxylated minerals [36] as a false color combination $\mathrm{RGB}=(2 / 1,3 / 2,5 / 7)$ was used [37]. The result is shown in Figure 3.

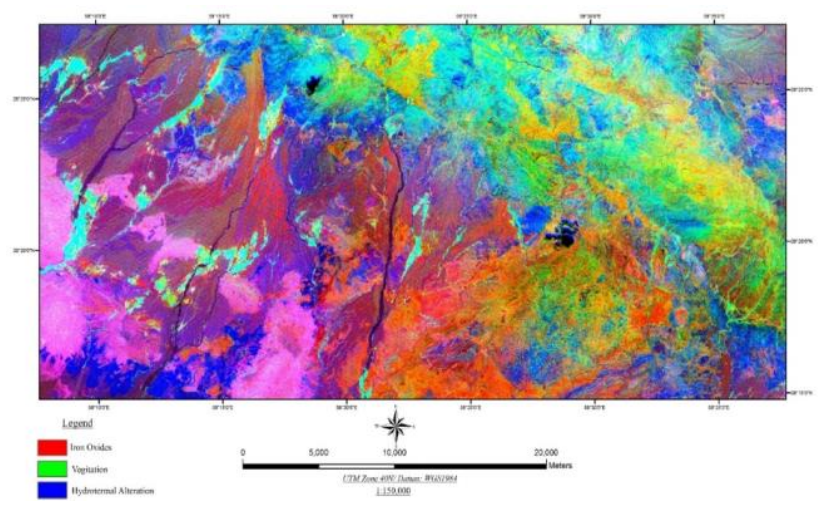

Figure. 3 false color combination image $\operatorname{RGB}=(2 / 1,3 / 2,5 / 7)$

In the resulting image, the pinky to red regions indicate the presence of iron oxides, the green to yellow zones indicate the presence of vegetation and eventually the blue zones indicate the presence of clay minerals.

\subsection{False Color Combinations Method}

In the study area, a false color combination $(4,6,8)$ RGB was used [35]. and the result is shown in Figure 4.

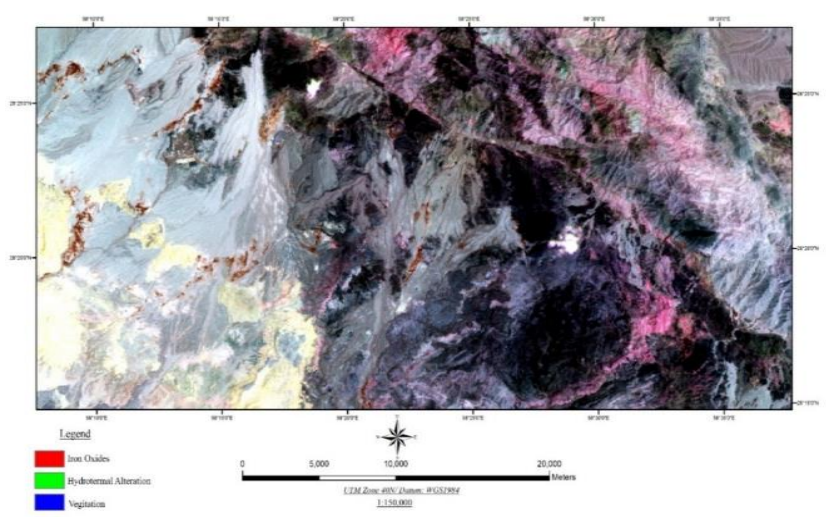

Figure. 3 false color combination image $\operatorname{RGB}=(4,6,8)$

\subsection{Principal Components Analysis (PCA)}

In the study area, the combination of bands $3,2,1$ and 4 was used to show areas containing iron oxides. The statistical results and their PC coefficients are shown in Table 1.

Table 1. The statistical results and PC coefficients related to the ASTER bands composition.

\begin{tabular}{|c|c|c|c|c|}
\hline Band 4 & Band 3 & Band 2 & Band 1 & \\
\hline 0.128783 & 0.456589 & 0.639967 & 0.60447 & PC1 \\
\hline-0.335408 & -0.794281 & 0.191027 & 0.469178 & PC2 \\
\hline $\mathbf{0 . 9 3 2 6 0 5}$ & -0.385483 & 0.007555 & 0.061825 & PC3 \\
\hline-0.034116 & -0.185138 & 0.744241 & -0.640832 & PC4 \\
\hline
\end{tabular}

Looking at Table 1, it can be seen that the greatest difference between the absorption bands and the reflection of the iron oxide index appears in the third component.Therefore, the component can be used to show the probable areas containing iron oxides (Figure 4).

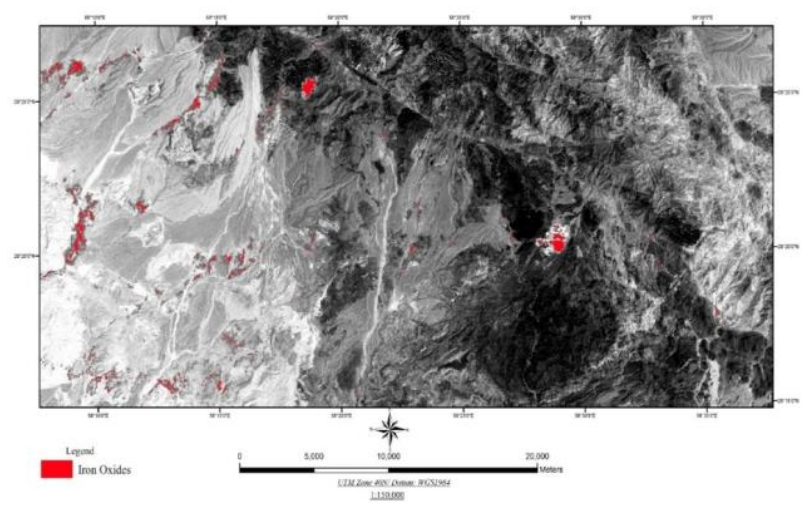

Figure. 4 The third component image (PC3) obtained after analyzing the principals components.

The red regions in the figure 4 shows regions containing iron oxides. Which are separated by PCA method. 


\subsection{Least Square Fitting (LS-Fit) Method}

In this study, band 2, which has high adsorption index for iron oxide minerals, was selected as model band and other bands were selected as the predictor bands. The final image is shown in Figure 5. The blue regions that are separated on the ASTER image are regions containing iron oxide (see figure 5).

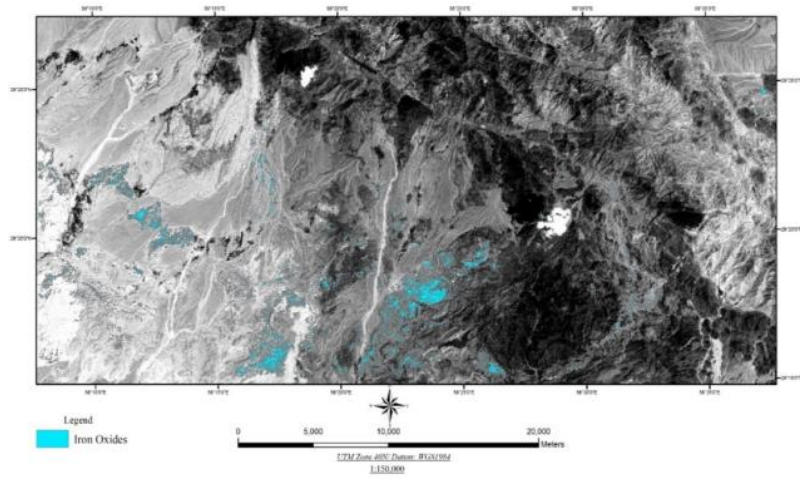

Figure. 5 The result of applying the Ls-Fit method.

\subsection{Spectral Angle Mapper (SAM) Method}

In the study area, using the spectral angle mapper base pixel method and using the spectral library, the hematite and limonite iron minerals were detected and shown in (Figures 6 and 7).

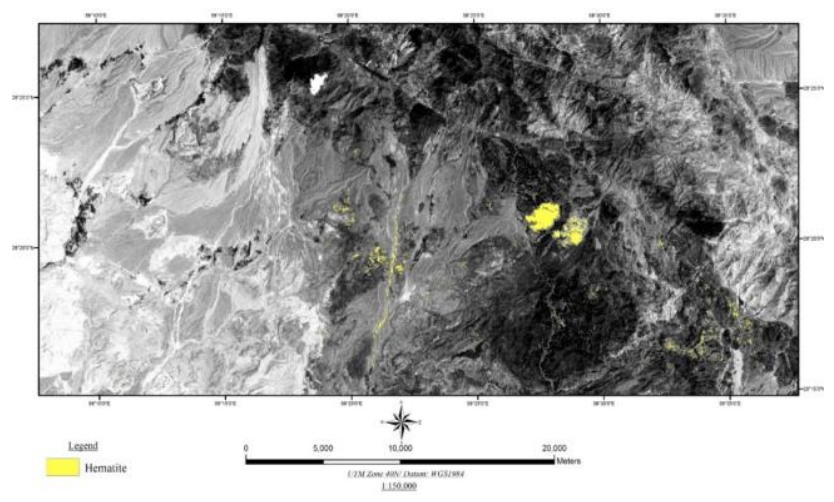

Figure 6. Hematite Separation Using Spectral Angle Mapper Method.

The yellow regions marked on the ASTER image (figure 6) are regions containing Hematite Cannabis, that are separated by Spectral Angle Mapper (SAM) Method.

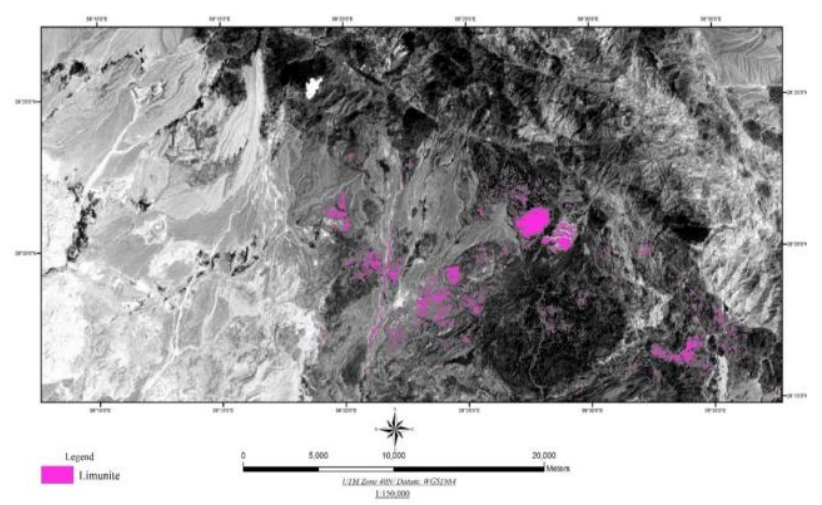

Figure 7. Limonite Separation Using Spectral Angle Mapper Method.
In figure 7 , regions containing limonite, are indicated with purple color.

\subsection{Field Studies and Control Point}

After the remote sensing tests were carried out and the results were obtained. Regarding the determination of areas as iron oxides by various techniques. One point was determined as a control point and was referred to the position for checking the results. This point is a place designated by the Spectral Angle Mapper (SAM) Method as the region containing hematite and limonite minerals. While other methods used in this region, indicate the lack of iron oxide there. The location of the control point is shown in Figure 8.

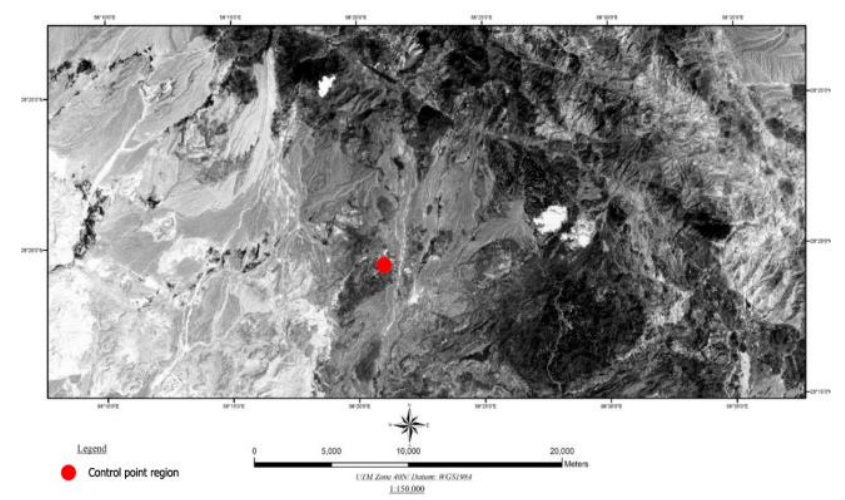

Figure 8. The location of the control point on the ASTER image.

After checking the control point, it was found that there is hematite and limonite mineralization in this region. The control point and mineralization of hematite and limonite is shown in Figure 9.

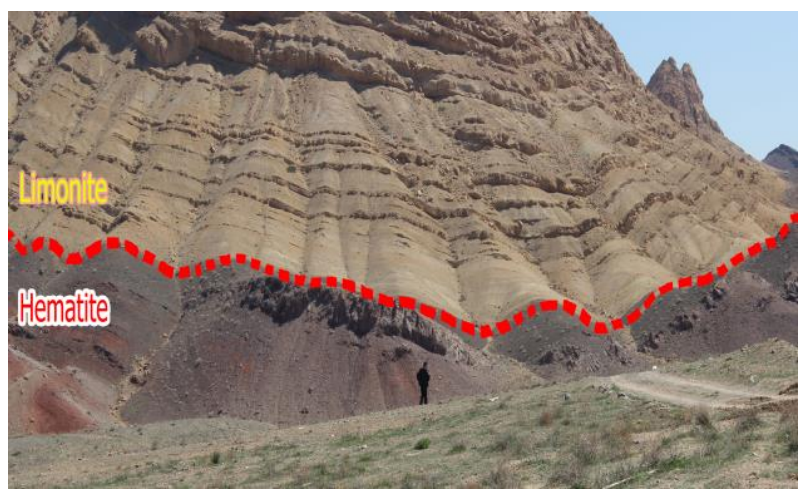

Figure 9. image of the control point in the field.

Hematite mineralization in lower layers and limonite mineralization in upper layers.

\section{CONCLUSION}

- The importance of exploration of iron ore is obvious because it is an economic and strategic element. In this regard, remote sensing has been used as one of the most important tools in the exploration of these minerals.

- In this study, using remote sensing methods including band ratios (BR), false color combinations (FCC), least square fitting (LS-Fit), spectral angle mapper (SAM), and principal components analysis (PCA) and also 
considering the geological features of the study area, the detection of oxidation regions and iron minerals in the area of Hana, located in the south of Kerman province, was discussed.

- After examining the field evidence in the control point, it was determined that the Spectral Angle Mapper (SAM) Method can be cited and closer to the reality in this study area for iron remote sensing. In the results of this method, the regions were identified that contain mineralization of hematite and limonite. While these points were free from iron oxide in the images obtained from other methods.

- The overall results of this study, in addition to showing the high accuracy of the SAM method, show the importance of using remote sensing methods and techniques in exploration and prospecting of minerals, especially iron ore.

\section{REFERENCES}

[1] Singla, A., Ahuja, I., \& Sethi, A. (2017). The effects of demand pull strategies on sustainable development in manufacturing industries. International Journal of Innovations in Engineering and Technology, 8(2), 27-34. http://dx.doi.org/10.21172/ijiet.82.005

[2] Afaghi, A., Sadjedi, T., Salek, M. M., \& StamenKovic, D. (Cartographer). (1973). Geological Map of IRAN 1:100000 Sheets Series, Hana Sheet 7645

[3] Roonwal, G. S. (2018). Mineral Exploration: Practical Application: Springer.

[4] Shivakumar, V., Pokhrel, S., \& Parekh, A. (2017). Block-1 Introduction to Remote Sensing: IGNOU.

[5] Arivazhagan, S., \& Anbazhagan, S. (2017). ASTER Data Analyses for Lithological Discrimination of Sittampundi Anorthositic Complex, Southern India. https://dx.doi.org/10.22606/gr.2017.23005

[6] Obata, K., Tsuchida, S., Yamamoto, H., \& Thome, K. (2017). Cross-Calibration between ASTER and MODIS Visible to Near-Infrared Bands for Improvement of ASTER Radiometric Calibration. Sensors, 17(8), 1793. https://dx.doi.org/10.3390/s17081793

[7] Amer, R., Kusky, T., \& Ghulam, A. (2010). Lithological mapping in the Central Eastern Desert of Egypt using ASTER data. Journal of African Earth Sciences, 56(23), 75-82. https://doi.org/10.1016/j.jafrearsci.2009.06.004

[8] Padró, J.-C., Pons, X., Aragonés, D., Díaz-Delgado, R., García, D., Bustamante, J., . . . Cristóbal, J. (2017). Radiometric Correction of Simultaneously Acquired Landsat-7/Landsat- 8 and Sentinel-2A Imagery Using Pseudoinvariant Areas (PIA): Contributing to the Landsat Time Series Legacy. Remote Sensing, 9(12), 1319.

\section{https://doi.org/10.3390/rs9121319}

[9] Bransden, B. H., \& Joachain, C. J. (2003). Physics of atoms and molecules: Pearson Education India.
[10] Zhao, B., Shao, G., Fan, B., Zhao, W., Xie, Y., \& Zhang, R. (2015). Synthesis of flower-like CuS hollow microspheres based on nanoflakes self-assembly and their microwave absorption properties. Journal of Materials Chemistry A, 3(19), 10345-10352. https://doi.org/10.1039/c5ta00086f

[11] Gupta, R. P. (2017). Remote sensing geology: Springer.

[12] Dhara, M., Sengar, V. K., Chattoraj, S. L., \& Bhattacharjee, S. (2017). Mapping of Alteration Zones in Mineral Rich Belt of South-East Rajasthan Using Remote Sensing Techniques. World Academy of Science, Engineering and Technology, International Journal of Environmental, Chemical, Ecological, Geological and Geophysical Engineering, 11(2), 154-158.

[13] Safari, M., Maghsoudi, A., \& Pour, A. B. (2017). Application of Landsat- 8 and ASTER satellite remote sensing data for porphyry copper exploration: a case study from Shahr-e-Babak, Kerman, south of Iran. Geocarto International, 1-16.

http://dx.doi.org/10.1080/10106049.2017.1334834

[14] Gahlan, H., \& Ghrefat, H. (2018). Detection of Gossan Zones in Arid Regions Using Landsat 8 OLI Data: Implication for Mineral Exploration in the Eastern Arabian Shield, Saudi Arabia. Natural Resources Research, 27(1), 109-124. http://dx.doi.org/10.1007/s11053-017-9341-8

[15] Garg, V., Kumar, A. S., Aggarwal, S., Kumar, V., Dhote, P. R., Thakur, P. K., . . Muduli, P. R. (2017). Spectral similarity approach for mapping turbidity of an inland waterbody. Journal of hydrology, 550, 527-537. https://doi.org/10.1016/j.jhydrol.2017.05.039

[16] Abdelaziz, R., El-Rahman, Y. A., \& Wilhelm, S. (2018). Landsat- 8 data for chromite prospecting in the Logar Massif, Afghanistan. Heliyon, 4(2), e00542. https://doi.org/10.1016/j.heliyon.2018.e00542

[17] Masoumi, F., Eslamkish, T., Honarmand, M., \& Abkar, A. A. (2017). A Comparative Study of Landsat-7 and Landsat-8 Data Using Image Processing Methods for Hydrothermal Alteration Mapping. Resource Geology, 67(1), 72-88 https://doi.org/10.1111/rge.12117

[18] Yao, K., Pradhan, B., \& Idrees, M. O. (2017). Identification of rocks and their quartz content in gua musang goldfield using advanced spaceborne thermal emission and reflection radiometer imagery. Journal of Sensors, 2017. https://doi.org/10.1155/2017/6794095

[19] Hereher, M. E., \& Abdullah, S. E. (2017). Lithologic mapping of Aja granitic batholiths, Ha'il, Saudi Arabia, using remote sensing. Arabian Journal of Geosciences, 10(14), 313.

http://dx.doi.org/10.1007/s12517-017-3101-2

[20] Razmi, M., Asgari, H. M., Sohrab, A. D., Nazemosadat, S. M. J., \& Khazaei, S. H. (2017). Monitoring oscillations coastline of Dayyer city during the El Niño and La Niño using OIF utility index. 
[21] Abbaszadeh, M. (2010). Mapping hydrothermal alterations using ASTER images in Parkam area, Kerman. GEOSCIENCES, 78.

[22] Hooshyari, N. (2005). Separation of alteration zones in relation to possible mineralization of gold and copper Zofre area using satellite data ASTER. (BSc), Isfahan University of Technology.

[23] Manuel, R., Brito, M. d. G., Chichorro, M., \& Rosa, C. (2017). Remote Sensing for Mineral Exploration in Central Portugal. Minerals, 7(10), 184. http://dx.doi.org/10.3390/min7100184

[24] Wang, G., Du, W., \& Carranza, E. J. M. (2017). Remote sensing and GIS prospectivity mapping for magmatichydrothermal base-and precious-metal deposits in the Honghai district, China. Journal of African Earth Sciences, 128, 97-115. https://doi.org/10.1016/j.jafrearsci.2016.06.020

[25] Gómez-Palacios, D., Torres, M. A., \& Reinoso, E. (2017). Flood mapping through principal component analysis of multitemporal satellite imagery considering the alteration of water spectral properties due to turbidity conditions. Geomatics, Natural Hazards and Risk, 8(2), 607-623.

https://doi.org/10.1080/19475705.2016.1250115

[26] Hassanipak, A. A., \& Sharafeddin, M. (2005). Exploration Data Analysis (Vol. 1). Tehran: Tehran university press.

[27] Soe, M., Kyaw, T. A., \& Takashima, I. (2005). Application of remote sensing techniques on iron oxide detection from ASTER and Landsat images of Tanintharyi coastal area, Myanmar.

[28] Vincent, R. K. (1997). Fundamentals of geological and environmental remote sensing (Vol. 366): Prentice Hall Upper Saddle River, NJ.

[29] Asadzadeh, S., \& de Souza Filho, C. R. (2016). A review on spectral processing methods for geological remote sensing. International journal of applied earth observation and geoinformation, 47, 69-90.

https://doi.org/10.1016/j.jag.2015.12.004

[30] Ramezanali, A., Mansouri, E., \& Feizi, F. (2017). Integration of aeromagnetic geophysical data with other exploration data layers based on fuzzy AHP and CA fractal model for $\mathrm{Cu}$-porphyry potential mapping: a case study in the Fordo area, central Iran. Bollettino di Geofisica Teorica ed Applicata, 58(1).

https://doi.org/10.4430/bgta0189

[31] Ezzati, A., Mehrnia, R., \& Ajayebi, K. (2014). Detection of Hydrothermal potential zones using remote sensing satellite data in Ramand region, Qazvin Province, Iran. Journal of Tethys, 2(2), 93-100.

[32] Hasan, E., Fagin, T., El Alfy, Z., \& Hong, Y. (2016). Spectral Angle Mapper and aeromagnetic data integration for gold-associated alteration zone mapping: a case study for the Central Eastern Desert Egypt.
International Journal of Remote Sensing, 37(8), 17621776.

https://doi.org/10.1080/01431161.2016.1165887

[33] Markovskiy, N. (2014). Drop-in Acceleration of GNU Octave.

[34] Esmaeeli, M., Tabaee, M., \& Asadiharooni, H. (2012). Remote Sensing Study (ASTER \& TM) and Geology of Southwest Meyme Iron Ore Deposit, IRAN. Paper presented at the 31st Symposium of Geosciences, Tehran, IRAN.

[35] Boloki, M., \& Poormirzaee, M. Using ASTER image processing for hydrothermal alteration and key alteration minerals mapping.

[36] van der Werff, H., \& van der Meer, F. (2015). Sentinel-2 for mapping iron absorption feature parameters. Remote Sensing, 7(10), 12635-12653. https://doi.org/10.3390/rs71012635

[37] Van Der Werff, H., \& Van Der Meer, F. (2016). Sentinel-2A MSI and Landsat 8 OLI provide data continuity for geological remote sensing. Remote Sensing, 8(11), 883.

https://doi.org/10.3390/rs8110883 